\title{
A Study on Javanese Learners of English and Compliment Response Strategies
}

\author{
Qanitah Masykuroh \\ Department of English Education, Universitas Muhammadiyah Surakarta \\ qm153@ums.ac.id
}

\begin{abstract}
The purpose of this study is to examine how Javanese English learners respond to complement tactics (JLE). Discourse completion tasks (DCT) were used to collect data from 25 JLE. In addition, answers to compliment tactics in Javanese were elicited from 25 native Javanese speakers (NJ) to establish a baseline for how their Javanese strategies influence JLE's strategies. The complement to response techniques was investigated using Yu's modified response taxonomy (2004). The findings demonstrate that both JLE and J.N. employ the standard acceptance method, which includes appreciation tokens, agreement, downgrade, query, transfer, return, transfer, and a variety of sub-strategies. Furthermore, the data suggest that JLE's praise responses may reflect the impact of Javanese culture on their English usage. Similarly, global change has altered Javanese natives' complement response tactics, with J.N. appearing to respond to compliments in ways that are not constrained by Javanese cultural standards.
\end{abstract}

Keywords: compliment responses, strategies, Javanese, EFL learners

\section{Introduction}

Compliments are a universal speech act that includes both giving and receiving them. Compliment is defined as "a spoken act that expressly or implicitly bestows credit onto the addressee for any property, skill, characteristic, or the like, the speaker and addressee positively appraise that." As a result, to be regarded as a complement, an utterance must allude to something that the participants esteem highly and ascribe to the addressees [2]. Complementing behavior can develop or reinforce unity [3],[4]. Compliments can be used at any point in a conversation, including the start, middle, and end, and are frequently used as conversation openers and closings. Ignoring to provide praises could be interpreted as a sign of disapproval, and using compliments inappropriately can lead to embarrassment and even offense [5].

Although compliments are widely acknowledged as a universal speaking act, different cultures have distinct tactics for delivering and responding to compliments. [6],[7]. When responding to a compliment, speakers must not only agree with the compliments given to them, but they must also avoid self-praise, which can be difficult for the speakers. Participants in a conversation must strike a balance between agreeing with others' compliments and refraining from self-praise [8]. In this study, English speakers and Javanese speakers had different complement response methods. Avoiding self-praise is more important in Javanese culture. Cross-cultural variations cannot be overlooked when it comes to pragmatics. As a result, people do not generally speak in the same way at all times. As a result, while studying talks, elements such as power and distance, age, sex, and ethnic identities, as presumed by linguistics, must be examined [9][10].

Referring to American society, divided compliment responses into acceptance and refusal. [12] agreed with [11] that declining praises would be regarded face-threatening. When people receive compliments, [13] suggests that they may face two separate difficulties. Compliments 
are frequently interpreted as assessments, and people appear to feel pressured to agree with the assessment [13]. Another issue is whether to accept the compliment, which may portray them as self-congratulatory, or reject the complement, which shows a disagreement with the speaker's good and positive intentions and may be viewed as disrespectful.

Several research have been conducted on features of compliment replies in EFL students. [14-16] highlight the pragma-linguistic transfer, which highlights how EFL learners respond to compliments, whereas [17] focuses on EFL learners' sociolinguistic ability in responding to compliments. Similarly, [13][18] concentrate on the linguistic characteristics of the compliment and compliment answer expression, [21] on the gender variations in compliment responses, and [19][20] on the cultural differences in compliment responses. The tactics of speakers of regional languages learning English as a foreign language remain unstudied among the elements of EFL learners' responses to compliments.

Given that compliments lubricate the social wheels [2] it's worth looking at the possible patterns of how Javanese English learners respond to compliments and how their methods differ from those used in the Javanese language. The findings of this study may help English teachers in Java assist Javanese English learners in responding to compliments in English in a more acceptable manner, as well as contributing to the social pragmatic understanding of Javanese English learners.

\section{Research Methods}

The data of this study were elicited through discourse completion tasks (DCT) from 25 JLE (Javanese learners of English). In addition, responses to compliment strategies in Javanese were elicited through DCT from 25 native speakers of Javanese (N.J.) to provide the baseline of how JLE's strategies of compliment response are influenced by their Javanese language. The participants are university students of $3^{\text {rd }}$ semester, aged between 19-21 years old. Prior to the participants' completing the DCT, briefing were given and consent forms were distributed to be signed by the participants as they agreed to participate in the study.

The data obtained from DCT may not provide a fully authentic picture of what the subjects have actually said in real-life situations. Nevertheless, the data should be able to reflect the norms which the group of target subjects keeps to. Besides, since the responses are presented in written forms, the phonological aspects were not discussed. The DCT consists of 20 scenarios with four topics of compliment i.e. appearance, possession, achievement and attitude. Additionally, the context situation is informal, and the familiarity between participants, the distance, is the focus when investigating the variable that may change the way a compliment recipient responds to a compliment. The data were analyzed based on a modified response taxonomy proposed by [17].

Table 1. Coding scheme on compliment response strategies, modified from Yu (2005) 


\begin{tabular}{|c|c|}
\hline Strategies & Sub-strategies \\
\hline \multirow{4}{*}{$\begin{array}{l}\text { Acceptance } \\
\text { strategies: the remark } \\
\text { is recognized as a } \\
\text { compliment }\end{array}$} & 1. Appreciation token: words showing gratitude \\
\hline & 2. Agreement: agree with the compliment \\
\hline & 3. Pleasure: show the complimentee is pleased \\
\hline & 4. Association: more than one of the Acceptance sub strategies above \\
\hline \multirow{7}{*}{$\begin{array}{l}\text { Amendment } \\
\text { strategies: the speaker } \\
\text { tries to amend its } \\
\text { complimentary force }\end{array}$} & 1. Return: reciprocate the compliment by offering praise \\
\hline & 2. Downgrade: scale down the compliment \\
\hline & 3. Upgrade: increase the force of the compliment \\
\hline & 4. Question: question the sincerity or appropriateness \\
\hline & $\begin{array}{l}\text { 5. Comment: do not take credit for it but impersonalize the force of } \\
\text { the compliment }\end{array}$ \\
\hline & 6. Transfer: switch the force or the focus back to the complimenter \\
\hline & 7. Association: include two or more of the Amendment strategies \\
\hline \multirow{4}{*}{$\begin{array}{l}\text { Non acceptance } \\
\text { strategies: deny, } \\
\text { question, or joke } \\
\text { about the content of } \\
\text { the compliment }\end{array}$} & 1. Disagreement: disagree with the assertion of the compliment \\
\hline & $\begin{array}{l}\text { 2. Qualification: do not accept the compliment by questioning the } \\
\text { quality that is praised }\end{array}$ \\
\hline & $\begin{array}{l}\text { 3. Diverge: question the compliment by suggesting other intended } \\
\text { acts }\end{array}$ \\
\hline & $\begin{array}{l}\text { 4. Association: include more than one of the Non acceptance sub } \\
\text { strategies }\end{array}$ \\
\hline
\end{tabular}

\section{Results and Discussion}

The aim of this study is exploring the possible compliment response strategies used by Javanese learners of English as well as Javanese Native. The participants carry the roles of the compliment recipients and are asked to respond to the compliments. The scenarios are supposed to be the possible situations JLE and N.J. will receive compliments. Moreover, the scenarios are designed intentionally to show complimenting among people relatively familiar in informal situation.

The situations with the peer (status equal) are situations in which the complimenters are friends, classmates or sibling of the complimentee. The compliment-response exchanges take place at campus or at home. Besides, there are also situations in the complimenters are teachers or coach with whom the complimentee are familiar, and mothers. Basically, in the situations, references to gender, age, nationality, and are avoided.

There are 12 scenarios in DCT in which the participants have a picture of where it is and what the relationship between the speakers is. The DCT is given to 20 participants comprising the topics of compliment of appearance, possession, achievement and attitude. Therefore, there are 60 responses to compliments for each topic, and totally, there are 240 responses analyzed. 
The analysis of DCT by Javanese learners of English indicates acceptance to the compliment as general strategy that JLE use in responding to compliment. The acceptance is mostly expressed by appreciation token with 162 responses on all topics of the compliment with the most occurrence is on the topic of attitude ( 52 responses) and the least occurrence is on the topic of appearance (31 responses). The appreciation token is mostly expressed by the phrase 'thanks', 'thank you' or 'O thank you'.

Following the appreciation token, other strategies of accepting compliment used by JLE is agreement (19 responses) which occur on the topic of possession and attitude. The agreement is generally expressed by restate the compliment as can be seen in the following example:

Speaker 1: "It's a new motorcycle, isn't it? It looks cool."

Speaker 2: "Yes, it's a new product, just launched last month"

In the conversation above, the compliment on the topic of possession (a new motorcycle) is accepted and responded by stating agreement on the new condition of the motorcycle. It is also followed by an association that gives more information on the topic complimented.

Though having fewer occurrences, amendment as a strategy to respond compliment is also used by JLE. The amendment is generally expressed by downgrading (19 responses), questioning (12 responses) and transfer (12 responses). Further, it is interesting to note that the amendment strategy by downgrading occurs only on the topic of possession and achievement, whereas question occurs only in the topic of appearance, and transfer occurs on the topic of achievement and attitude.

The amendment strategy by downgrading is usually done by decreasing the quality of the topic complimented, from 'being excellent' to 'being trivial', as can be seen in the following example:

Speaker 1: "Your writing is excellent, I like it"

Speaker 2: "It's just a trivial thing"

Question is usually expressed by phrases 'really', 'Isn't it', 'Are you sure', and 'Are you kidding?' and transfer are expressed by reattributing the compliment to other recipients. In addition to the general strategies of accepting the compliment, some JLE also use disagreement to respond the compliment. This occurs only on the topic of appearance.

Speaker 1: "You look charming wearing that shirt"

Speaker 2: "I don't think so"

In the dialog above, the complimentee did not accept the compliment by disagreeing on the topic complimented. The disagreement is expressed by the expression 'I don't think so'. Similarly, the responses to compliment showing the non-acceptance strategy are mostly expressed by such a phrase with a variation of 'I don't believe it'. The summary of the strategies used by Javanese learners of English in responding to compliments can be seen in table 2 . 
Table 2. Strategies of compliment responses in English by Javanese English Learners

\begin{tabular}{|c|c|c|c|c|c|c|c|c|c|c|c|c|c|c|c|c|}
\hline & \multicolumn{16}{|c|}{ Topic of compliment } \\
\hline & \multicolumn{4}{|c|}{ Appearance } & \multicolumn{4}{|c|}{ Possession } & \multicolumn{4}{|c|}{ Achievement } & \multicolumn{4}{|c|}{ Attitude } \\
\hline Sub Strategies & 1 & 2 & 3 & 4 & 1 & 2 & 3 & 4 & 1 & 2 & 3 & 4 & 1 & 2 & 3 & 4 \\
\hline Appreciation token & 31 & & & & 40 & & & & 39 & & & & 52 & & & \\
\hline Agreement & & & & & 15 & & & & & & & & 4 & & & \\
\hline Pleasure & & & & & & & & & & & & & & & & \\
\hline Association & & & & & & & & & & & & & & & & \\
\hline Return & & 9 & & & & & & & & & & & & & & \\
\hline Downgrade & & & & & & 5 & & & & 13 & & & & & & \\
\hline Upgrade & & & & & & & & & & & & & & & & \\
\hline Question & & 12 & & & & & & & & & & & & & & \\
\hline Comment & & & & & & & & & & & & & & & & \\
\hline Transfer & & & & & & & & & & 8 & & & & 4 & & \\
\hline Association & & & & & & & & & & & & & & & & \\
\hline Disagreement & & & 8 & & & & & & & & & & & & & \\
\hline Qualification & & & & & & & & & & & & & & & & \\
\hline Diverge & & & & & & & & & & & & & & & & \\
\hline
\end{tabular}

1= Acceptance $; 2=$ Amendment $3=$ Non Acceptance $;$ 4= Commodification

Similar to JLE, Javanese native generally use acceptance as their compliment response strategy. The acceptance is expressed by appreciation token (95 responses), agreement (27 responses), return (14 responses), question (23 responses), transfer (24 responses) and disagreement (19 responses). The appreciation token occurs on all topics, whereas agreement occurs in the topic of possession and achievement; return occurs in the topic of appearance and attitude; question occurs in the topic of appearance and possession; transfer occurs in the topic of achievement and attitude and disagreement occurs in the topic of appearance, possession and achievement. The summary of the strategies deployed by Javanese native can be seen in table 3.

Table 3. Strategies of compliment responses in Javanese

\begin{tabular}{|l|c|c|c|c|c|c|c|c|c|c|c|c|c|c|c|c|}
\hline & \multicolumn{10}{|c|}{ Topic of compliment } \\
\hline & \multicolumn{9}{|c|}{ Appearance } & \multicolumn{9}{c|}{ Possession } & \multicolumn{3}{c|}{ Achievement } & \multicolumn{3}{c|}{ Attitude } \\
\hline Sub Strategies & 1 & 2 & 3 & 4 & 1 & 2 & 3 & 4 & 1 & 2 & 3 & 4 & 1 & 2 & 3 & 4 \\
\hline Appreciation & 12 & & & & 10 & & & & 33 & & & & 40 & & & \\
\hline Agreement & & & & & 26 & & & & 1 & & & & & & & \\
\hline Pleasure & & & & & & & & & & & & & & & & \\
\hline
\end{tabular}




\begin{tabular}{|l|l|l|l|l|l|l|l|l|l|l|l|l|l|l|l|l|}
\hline Association & & & & & & & & & & & & & & & & \\
\hline Return & & 18 & & & & & & & & & & & & 4 & \\
\hline Downgrade & & & & & & 17 & & & & 8 & & & & & & \\
\hline Upgrade & & & & & & & & & & & & & & & & \\
\hline Question & & 20 & & & & 3 & & & & & & & & & & \\
\hline Comment & & & & & & & & & & & & & & & & \\
\hline Transfer & & & & & & & & & & 15 & & & & 4 & & \\
\hline Association & & & & & & & & & & & & & & & & \\
\hline Disagreement & & & 10 & & & & 4 & & & 5 & & & & & & \\
\hline Qualification & & & & & & & & & & & & & & & & \\
\hline Diverge & & & & & & & & & & & & & & & & \\
\hline
\end{tabular}

1= Acceptance $; 2=$ Amendment $3=$ Non Acceptance $; 4=$ Commodification

Furthermore, the appreciation token is expressed by general expression of gratitude in Javanese 'nuwun' and 'maturnuwun', while the expressions of question are 'mosok', 'ah mosok', 'mosok to', opo iyo', 'tenane', and 'ah tenane'. The following is an example of how the complimentee questions the compliment:

Speaker 1: "Klambimu ketok apik, kuwi klambi anyar ya?"

(Your dress looks good, it is new, isn't it?"

Speaker 2: "Mosok to, sing apik apane?"

(Really, what is good on this dress?"

In the conversation above, the complimentee question the compliment by asking the aspect of quality of something being complimented i.e. the dress. In addition to the acceptance, it is interesting to find out that Javanese native also use non-acceptance strategy in responding to compliment. The strategy is mostly expressed by disagreement. The expression of the disagreement used by J.N. is the variation of the following expression showing negation 'No': 'Halah, ora yo', "Ojo ngono Bro”, Ora ya', 'Mboten', 'Ora koq', 'Ojo ngece kowe', and 'Ora $i k^{\prime}$

Speaker 1: "Garapanmu apik banget ki, mengko lak bijine A"

(Your work is excellent; you must get A)

Speaker 2: "Halah ora yo" (No, it doesn't)

The sorts of replies employed by both JLE and J.N. participants are: (1) appreciation token; (2) agreement; (3) downgrade; (4) question; (5) transfer, (6) return, and (7) transfer, according to data analysis. However, because JLE's answer is dominated by token appreciation, it appears that they follow the English culture's paradigm: I want to respect and appreciate when people say nice things about me, but I don't want to expressly agree with nice things other people said to me (Yan Huang 2014).

When this pattern is followed, expressing thanks is the initial response to an English compliment. J.N., on the other hand, accepts the compliment but replies by directly expressing their agreement or by declining the compliment. This can be understood by considering that, 
just as compliments differ by culture, so do responses to them. When accepting compliments, Indonesians may consider "thank you" to be the sole acceptable response. This occurs because Indonesians are not accustomed to elevating themselves. The majority of the time, Indonesians reject compliments by reducing their own quality on the commended items. According to [22], when learning English, Javanese learners of English may be influenced by Javanese culture, which places a high priority on modesty. This may lead them to speak according to their own set of rules. They may reject compliments rather than receive them. As a result, rather than saying "thank you," they may say "oh, no" [22].

Furthermore, rapid changes in lifestyle and technological advancements may be factors influencing Javanese learners' varied language usage. Because the participants are young people who have been the primary market for new digital technology and global change, their use of the Javanese language is influenced to some extent by their interactions with speakers of other languages on social media platforms such as Twitter, Facebook, and WhatsApp.

The Javanese culture that underpins the use of the Javanese language appears to be mingled with world culture. 'Ora yo Bro (No, buddy) is an example of how a Javanese learner declines a compliment, which is not following the traditional Javanese culture of keeping the 'rasa (feeling)' of other people by using mixed language in which 'Ora yo (no)' is a Javanese word, and 'Bro (brother)' is an English word that has become a youth address term nation-wide in Indonesia. In addition to Javanese adaptation to global culture and language, this indicates to varying degrees that Javanese underlying principles in social interaction, such as kurmat (respect), andhap asor (low profile), empan papan (well-positioned), and tepa slira (empathetic), as renowned by [23] [24], are losing favor with the younger generation of Javanese.

\section{Conclusion}

According to the findings, both English learners and native Javanese respond to praises in a way that appears to be a hybrid. They employ the standard acceptance approach, with varying frequency of substrategies. Furthermore, the study suggests that JLE's use of compliment responses may be impacted by their Javanese culture. This is especially evident in the usage of inquiry and disagreement as a method for reacting to compliments, which is not common in English, where the dominant strategy for responding to compliments is expressing appreciation. Javanese natives, on the other hand, are influenced by global change, which manifests itself in their usage of the Javanese language. Individuals's perspectives, attitudes, personalities, and communication behavior are changing as a result of rapid advancements in information and communication technology, which has offered people with limitless and better access to learn about various languages and cultures. As a result, the J.N. appears to respond to compliments offered more freely than the cultural norm with which they are associated. The attitudes and opinions of the young generation of Javanese speakers in executing the complement response speech act are diverse, according to this article. As a result, this will have an impact on their extensive interaction with global cultures and their practical adaption of contemporary ideals. 


\section{References}

[1] P. Hobbs, "The medium is the message: Politeness strategies in men's and women's voice mail messages". Journal of Pragmatics, Vol. 35, No. 2, pp 243-262, 2003.

[2] J. Holmes, An Introduction to Sociolinguistics, New York: Longman Group, 1992.

[3] J. Manes and N. Wolfson, The compliment formula in F Coulmas (Ed.) Conversational Routine: Explorations in Standardized Communication Situations and Prepatterned Spech, Netherlands: Mouton Publishers, 1981.

[4] M. E. Placencia and A. Lower, Compliments and compliment Responses in Hoffmann, C. and Bublitz, W. (eds.) Pragmatics of Social Media. Handbooks of Pragmatics (HOPS) 11, Berlin: De Gruyter, pp. 633-660, 2017.

[5] Z. Alsuhaibani, "Developing EFL students' pragmatic competence: The case of compliment responses”, Language Teaching Research online, Vol.00, No. 0, pp 1-20, 2020. doi:10.1177/1362168820913539

[6] N. Ishihara, "Giving and responding to compliments in K. Bardovi-Harlig \& R. Mahan Taylor (Eds.), Teaching pragmatics, Washington DC: Office of English Programs, U.S. Department of State, 2013.

[7] C.E. Stoian, "Speech Acts across Cultures: Teaching Compliment Exchanges", East-West Cultural Passage, Vol. 1, pp 144-162, 2020.

[8] A.H. Shaari Hani and M. Maros, "Compliments and compliment responses across borders: language and cultural change among the new generation of malays", E-Bangi Journal of Social Sciences and Humanities, Vol. 12, No. 1, pp 029-042, 2017.

[9] I. Istifci, "Comparison of Chinese and Turkish EFL learners on the use of compliment responses", Journal of Language and Linguistic Studies, Vol. 3, No.2, pp 14-29, 2017.

[10] E. Flores-Salgado and T. Witten. "A comparative study of Mexican and Irish compliment responses" Colombia Applied Linguisti Journal, Vol. 21, No.1, pp 125-138, 2019.

[11] A. Pomerantz, Compliment Responses. Notes on the Co-operation of Multiple Constraints in J. Schenkein (Ed.), Studies in the Organization of conversational Interaction pp 79-112, New York: Academic Press. 1978.

[12] K. Urano, Negative pragmatic transfer in Compliment Responses by Japanese Learners of English, Unpublished term paper submitted to ESL 660 University of Hawaii Manoa, 1998.

[13] A. Golato, Compliments and Compliment Responses: Grammatical Structure and Sequential Organization studies in Discourse and Grammar, Amsterdam: John Benjamins, 2005.

[14] R. Nafise, "A Contrastive Study of Compliment Responses among Australian English and Iranian Persian Speakers", PROCEDIA: Social and Behavioural Sciences, Vol. 70, pp 61-66, 2013

[15] Y. Sari, "Compliment Responses Used by Indonesians Learning English Based on the Compliment Topics and Social Statuses”, CELT Journal Vol. 9, No.2, pp 126-149, 2009.

[16] P. Sophie, "Compliment Responses of Female German and Italian University Students: A Contrastive Study", Language Studies Working Papers Vol. 5, pp 22-31, 2013.

[17] C. Yu Ming, "Sociolinguistic Competence in the Complimenting Act of Native Chinese and American English Speakers: A Mirror of Cultural Value", Language and Speech, Vol. 48, No.1, pp 91-119, 2005.

[18] A. Golato, "German compliment responses" Journal of Pragmatics Vol. 34, No.5, pp 547-571, 2002.

[19] P. Cedar, "Thai and American responses to compliments in English", The Linguistics Journal, Vol 1, No.2, pp 6-28, 2006.

[20] N. Lorenzo-Dus, "Compliment responses among British and Spanish university students: A contrastive study", Journal of Pragmatics, Vol. 33, No. 1, pp 107-127, 2001.

[21] E. F. Mascuñana, M. J. T. Patron, W.S. Caturay and H.B. Duran, "Compliment Responses by College Male and Female Filipino Second Language Learners of English", Corpus Pragmatics, Vol. 3, No. 1, pp 67-91, 2018. doi:10.1007/s41701-018-00048-3

[22] J. Ibrahim and T. J. Riyanto, "A sociolinguistic study of compliment responses among Americans and for teaching English”, $k @ t a$, Vol. 2, No. 1, pp 21-30, 2004.

[23] A. Gunarwan, Pragmatik, Budaya, dan Pengajaran Bahasa [Pragmatics, Culture and Langiage 
Education] A paper presented at National Seminar of Semantics Surakarta Indonesia, 2004.

[24] A. Gunarwan, Pragmatik:Teori dan Kajian Nusantara. Jakarta: Universitas Atmajaya, 2007. 